\title{
The Effect of Growth Temperature and V/III Flux Ratio of MOCVD Antimony Based Semiconductors on Growth Rate and Surface Morphology
}

\author{
Ari Handono Ramelan ${ }^{1}$, Sayekti Wahyuningsih ${ }^{2}$ and Ewa Goldys ${ }^{3}$ \\ ${ }^{1}$ Physics Department, Faculty of Mathematics and Natural Sciences, Sebelas Maret University, Jl. Ir. Sutami No, 36A Surakarta, Indonesia. \\ ${ }^{2}$ Chemistry Department, Faculty of Mathematics and Natural Sciences, Sebelas Maret University, JI. Ir. Sutami No, 36A Surakarta, \\ Indonesia. \\ ${ }^{3}$ Physics Department, Macquarie University, Sydney NSW 2109, Australia.
}

\begin{abstract}
Epitaxial $\mathrm{Al}_{x} \mathrm{Ga}_{1-x} \mathrm{Sb}$ layers on $\mathrm{GaSb}$ and $\mathrm{GaAs}$ substrates have been grown by atmospheric pressure metalorganic chemical vapor deposition using TMAl, TMGa and TMSb. Nomarski microscope and a profiler were employed to examine the surface morphology and growth rate of the samples. We report the effect of growth temperature and V/III flux ratio on growth rate and surface morphology. Growth temperatures in the range of $520^{\circ} \mathrm{C}$ and $680^{\circ} \mathrm{C}$ and $\mathrm{V} / \mathrm{III}$ ratios from 1 to 5 have been investigated. A growth rate activation energy of $0.73 \mathrm{eV}$ was found. At low growth temperatures between 520 and $540^{\circ} \mathrm{C}$, the surface morphology is poor due to antimonide precipitates associated with incomplete decomposition of the TMSb. For layers grown on GaAs at $580^{\circ} \mathrm{C}$ and $600^{\circ} \mathrm{C}$ with a V/III ratio of 3 a high quality surface morphology is typical, with a mirror-like surface and good composition control. It was found that a suitable growth temperature and V/III flux ratio was beneficial for producing good AlGaSb layers. Undoped $\mathrm{AlGaSb}$ grown at $580 \mathrm{oC}$ with a $\mathrm{V} / \mathrm{III}$ flux ratio of 3 at the rate of $3.5 \mu \mathrm{m} /$ hour shows p-type conductivity with smooth surface morphology.
\end{abstract}

\section{Introduction}

Because of the corresponding wavelengths of the alloys of Gallium antimonide (GaSb) based compound semiconductors cover a wide spectral range from 1.24 $\mu \mathrm{m}(\mathrm{AlGaSb}$ or $\mathrm{AlGaAsSb})$ to $4.3 \mu \mathrm{m}$ (InGaAsSb), they have received increasing attention recently. Consequently, they became promising candidates for applications in long wavelength lasers and photodetectors for fibre optic communication systems [1]. However, due to free-carrier absorption, undoped-GaSb substrates have a strong absorption in the IR wavelength region of interest which is difficult to eliminaten [2]. Furthermore, $\mathrm{GaSb}$ substrates are more expensive than GaAs. Thus there is a strong interest in growing superlattices (SLs) on GaAs substrates. So far, molecular beam epitaxy (MBE) has been used as the major growth technology for InAs/ $\mathrm{GaSb}$ structures [3]-[5]. However, growth of the SLs by metalorganic chemical vapor deposition (MOCVD) is more challenging than that by MBE [6], [7] especially for the growth on GaAs substrates due to the $7.8 \%$ lattice mismatch between $\mathrm{GaAs}$ and $\mathrm{GaSb}$

It is ideal to grow the AlGaSb films on latticematched GaSb substrates. However, due to the lack of semi-insulating GaSb, undoped substrates have a strong free carrier absorption in the mid-IR wavelength region of interest, so that the substrate must be thinned for optimal device operation in the flip-chip mode. For this and commercial reasons, $\mathrm{GaAs}$ has been explored as a substrate for $\mathrm{GaSb} / \mathrm{AlGaSb}$ devices. Unfortunately, a lattice mismatch of approximately 7\% exists between $\mathrm{GaSb}$ and GaAs. Strain energy can be accommodated by misfit dislocations at the $\mathrm{GaAs} / \mathrm{GaSb}$ interface. This results in the propagation of threading dislocations through the epilayers [8]. Thus the growth of undoped high quality $\mathrm{GaSb} / \mathrm{AlGaSb}$ layers on GaAs substrate becomes a necessary process for preparing thin layers.

These films have usually been grown by liquid phase epitaxy or molecular beam epitaxy (MBE) with relatively little data available for growth of $\mathrm{AlGaSb}$ by metalorganic chemical vapor deposition (MOCVD) [9][13]. AlGaSb has proven to be a much more difficult material to grow by MOCVD than GaSb. The simple reason is the reactivity of $\mathrm{Al}$, which forms strong bonds with carbon [10]-[11]. It is not surprising then that frequently the MOCVD-grown AlGaSb and AlSb have been reported to exhibit poor electronic and optical properties.

In this work, a series of undoped AlGaSb samples are grown on semi-insulating GaAs substrates at different substrate temperatures and V/III flux ratios. There have been no reports on the effect of substrate temperature and V/III flux ratio on growth rate and surface morphology, so we prepared several samples with different V/III flux 
ratios. The growth rates and surface morphology $\mathrm{AlGaSb}$ by metalorganic vapor phase epitaxy were studied as functions partial pressures of precursors.

\section{Experimental procedure}

\subsection{Growth conditions}

The growth was carried out in a horizontal MOCVD reactor at atmospheric pressure. The precursors were trimethylaluminum (TMAl), trimethylgallium (TMGa) and trimethylantimony (TMSb) held at a temperature of $18,-9$ and $0^{\circ} \mathrm{C}$ respectively. Source materials were diluted in hydrogen to obtain a carrier gas velocity of 1 sccm in the reactor. The substrates were (100) semiinsulating GaAs. GaAs substrates were prepared by degreasing in trichloroethylene (TCE), rinsing in acetone and methanol. The use of de-ionized water was used for rinsing the samples. The GaAs substrate was etched in a standard solution of $\mathrm{H}_{2} \mathrm{SO}_{4}, \mathrm{H}_{2} \mathrm{O}_{2}$ and $\mathrm{H}_{2} \mathrm{O}(5: 1: 1)$ for 30 $\mathrm{s}$ [14]. The substrates were further rinsed in DI water and rapidly dried under a nitrogen jet. The V/III ratios were varied from 1 to 5 . The growths were performed in the range of 520 and $680^{\circ} \mathrm{C}$ measured by a thermocouple located inside the graphite susceptor. The actual temperature of thesubstrate surface is assumed to be lower due to the cooling effect of the cold carrier gas.

\subsection{Characterisation}

The surface morphologies of the grown epilayers were observed using Nomarski contrast microscopy. Thicknesses were measured using a Tencor Alpha Step 500 surface profiler. A stylus profilorneter was routinely employed to record the surface profile of etched AlGaSb samples. Alpha-Sep can scan the surface at various rates in the range of $0.04-5 \mu \mathrm{m} / \mathrm{sec}$ for a maximum scan distance of $1 \mathrm{~cm}$. The vertical and horizontal resolutions are $5 \mathrm{~nm}$ and $12.5 \mu \mathrm{m}$ radius respectively. For this study, the scan rate and scan distance were selected as 0.2 $\mu \mathrm{m} / \mathrm{sec}$ and $400 \mu \mathrm{m}$ respectively. The etch rate was obtained by dividing the etch depth from the profile by the etching duration. To measure surface textures, AlphaStep automatically calculated average roughness. However, due to the relatively low resolution, Alpha-Step was only able to determine the surface roughness of some samples. The lowest measurable average roughness is 5 nm.

\section{Results and discussion}

\subsection{Growth Rate}

The two growth parameters that most strongly affect the growth rates are the metalorganic sources partial pressure and the growth temperature. Growth rate is defined as the thickness of the epilayer deposited on a substrate during a certain period of growth. The effect of growth temperature, in the range $520-680^{\circ} \mathrm{C}$, on the growth rate was investigated by keeping others parameters constant.
Constant flow rates of $\mathrm{TMAl}=5.6 \mathrm{sccm}, \mathrm{TMGa}=19.1$ $\mathrm{sccm}$ and $\mathrm{TMSb}=83.6 \mathrm{sccm}$, or equivalent to $\mathrm{V} / \mathrm{III}=3$ were used.

Fig. 1 shows the temperature dependence of growth rates for $\mathrm{Al}_{0.05} \mathrm{Ga}_{0.95} \mathrm{Sb}$. In the low temperatures range up to $540^{\circ} \mathrm{C}$, kinetic processes of alkyl decomposition at the substrate surface limit decomposition. This is known as the kinetically controlled regime, where the growth rate depends on temperature (degree of pyrolysis) and very little dependence of growth rate on pressure was observed. A typical exponential relationship between growth rate and growth temperature was observed and the activation energy of $0.73 \mathrm{eV}$ was found. Ungermanns et al. [15] have found an activation energy of $0.80 \mathrm{eV}$ for AlSb growth using dimethylethylaminealane (DMEAAl) as the aluminium source.

The growth rate of $\mathrm{AlGaSb}$ increases monotonically from 540 to $600^{\circ} \mathrm{C}$, while that of arsenic-containing alloys is almost constant in the same temperature range. The difference in behaviour between arsenic and antimony-containing alloys is explained by taking into account the surface coverage of group $\mathrm{V}$ atoms during growth [16]. Sb atoms are excessively absorbed on the growth front because of the low vapour pressure. Since $\mathrm{Ga}$ and $\mathrm{Al}$ atoms tend to desorb from the excessively $\mathrm{Sb}$ absorbed surface, only a few Ga and Al species can contribute to the growth. This is known as the siteblocking effect. Therefore, a higher growth rate, for $\mathrm{Sb}$ containing alloys, will be obtained for lower Sb surface coverage condition by selecting higher growth temperatures and/or lower V/III ratio. However, the low surface coverage of $\mathrm{Sb}$ may lead to the formation of $\mathrm{Ga}$ droplets. For higher temperatures, in the range of $580^{\circ} \mathrm{C}$ to $600^{\circ} \mathrm{C}$ the growth rate is constant. This region is a mass transport limited (i.e. the growth rate is controlled predominantly by the concentration of the precursors), because of the complete pyrolysis of the TMGa and $\mathrm{TMSb}$ molecules. Further increase in the growth temperatures, leads to a decrease of the growth rate due to desorption of gallium and antimony from the growth surface. The growth rate is not only a function of the availability of atomic species and the rate at which the precursor fragments combine at the surface, but also depends on the carrier gas velocity and the partial pressure of the metalorganic sources [17].

The V/III ratio is another key parameter because both a deficiency and an excess of antimony ( $\mathrm{Sb}$ ) on the semiconductor surface leads to a strong degradation of the material quality. Fig.1 shows the growth rate for the $\mathrm{Al}_{0.05} \mathrm{Ga}_{0.95} \mathrm{Sb}$ films as a function of the V/III ratio. The data indicate that the growth rate is significantly dependent on V/III ratios. At V/III ratios below about 2 the growth rate is low, under $1.87 \mu \mathrm{m} /$ hour. As the $\mathrm{V} / \mathrm{III}$ ratio increases the growth rate increases to reach value of $3.54 \mu \mathrm{m} / \mathrm{min}$ near a V/III ratio of 3 . In this region, the availability of $\mathrm{Sb}$ appears to be the key factor controlling the growth rate. At higher V/III ratios the growth rate starts to decrease. The strong decrease of the growth rate with increasing TMSb (group V) is caused by excess antimony molecules (due to the low vapour pressure of TMSb) at the substrate surface which leads to 
a decrease to the number of surface sites available for $\mathrm{Al}$ and $\mathrm{Ga}$ adsorptions and a resulting absolute decrease in $\mathrm{Al}$ and $\mathrm{Ga}$ adatoms. This blocking of $\mathrm{Al}$ and $\mathrm{Ga}$ adatoms by excess $\mathrm{Sb}$ results in reduced growth rates. Similar behaviour was reported by Okuno et al. [18] for AlGaSb growth using TMAAl (trimethylaminealane), TMGa and TMSb.

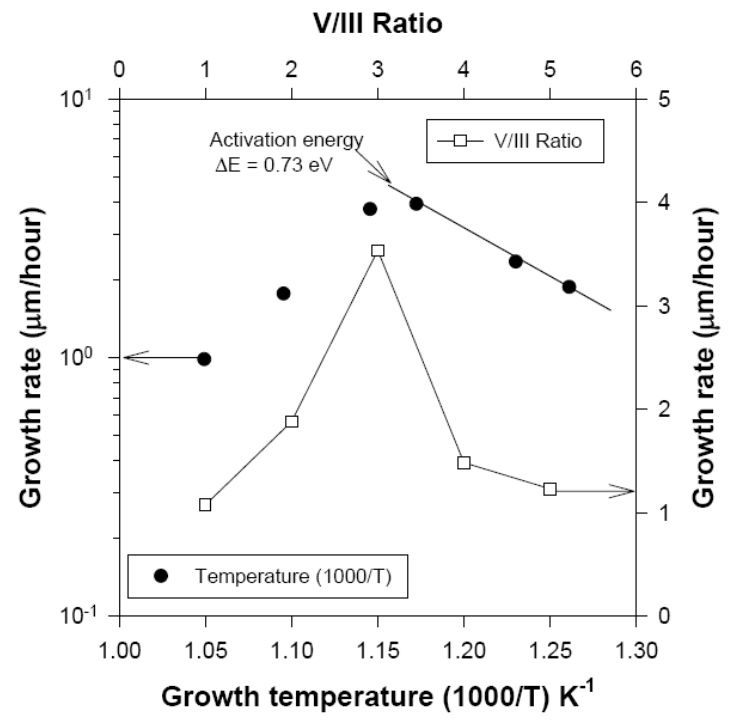

Figure 1. Temperature dependence of the $\mathrm{Al}_{0.05} \mathrm{Ga}_{0.55} \mathrm{Sb}$ growth rates and the growth rate of $\mathrm{Al}_{0.05} \mathrm{Ga}_{0.95} \mathrm{Sb}$ epilayers grown at $580^{\circ} \mathrm{C}$ as a function of $\mathrm{V} / \mathrm{III}$ ratio.

\subsection{Surface Morphology}

Fig. 2 shows the surface morphology of selected $\mathrm{Al}_{\mathrm{x}} \mathrm{Ga}_{1-\mathrm{x}} \mathrm{Sb}$ compositions for $\mathrm{V} / \mathrm{III}$ ratio $=3$ at $580^{\circ} \mathrm{C}$ and $600^{\circ} \mathrm{C}$ respectively. The morphology of $\mathrm{Al}_{\mathrm{x}} \mathrm{Ga}_{1-\mathrm{x}} \mathrm{Sb}$ on GaAs is mirror-like to the naked eye, but the epilayers exhibit microscopic well defined elongated features. As the Al-content increases, the surface texture changes and the elongated features disappear, to be replaced by featureless texture associated with the highest optical transmission. The interference fringe modulation depths of the epilayers obtained from transmission measurements confirm the high optical quality of the films grown at $580^{\circ} \mathrm{C}$. With further increase of Alcontent, several vessel-shaped structures appear on the epilayer surface. It has been found for this project that the $\mathrm{Al}_{\mathrm{x}} \mathrm{Ga}_{1-\mathrm{x}} \mathrm{Sb}$ layers grown at $580^{\circ} \mathrm{C}$ and $600^{\circ} \mathrm{C}$ and $\mathrm{V} / \mathrm{III}$ $=3$ with $\mathrm{Al}$ composition in the range of $0.5 \%$ and $30 \%$ are highly regular and accompanied by excellent optical quality, with a very high optical transmission at energies below the bandgap.

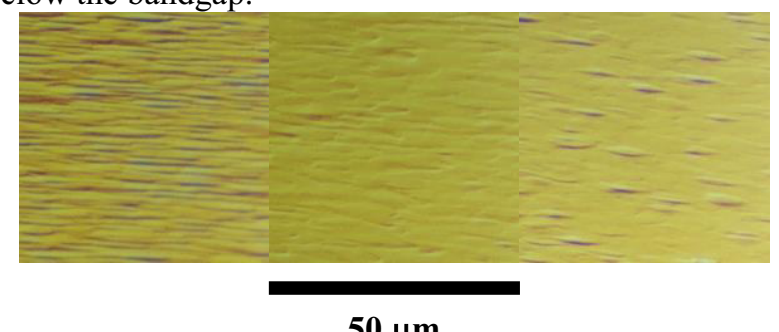

(i) $x=10 \%$ (ii) $x=20 \%$ (iii) $x=25 \%$

(a) Samples grown at $580^{\circ} \mathrm{C}$

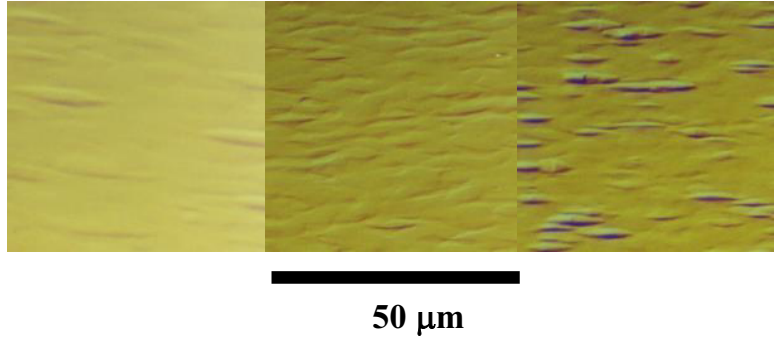

(i) $x=15 \%$ (ii) $x=20 \%$ (iii) $x=25 \%$

(b) Samples grown at $600^{\circ} \mathrm{C}$

Figure 2. Surface morphology of $\mathrm{Al}_{\mathrm{x}} \mathrm{Ga}_{1-\mathrm{x}} \mathrm{Sb}$ epilayers grown on GaAs with a different Al-content grown at $580^{\circ} \mathrm{C}$ and $600^{\circ} \mathrm{C}$ with a V/III ratio of 3 .

\section{Summary}

We have found that the $\mathrm{Al}_{\mathrm{x}} \mathrm{Ga}_{1-\mathrm{x}} \mathrm{Sb}$ layers grown at $580^{\circ} \mathrm{C}$ and $600^{\circ} \mathrm{C}$ and at a V/III ratio of 3 with $\mathrm{Al}$ composition in the range of $0.5 \%$ and $25 \%$ have excellent optical quality with a very high optical transmission at energies below the bandgap. In the low temperature range up to $580^{\circ} \mathrm{C}$, the growth rate depends on temperature (degree of pyrolysis of precursors) and the growth rate of $\mathrm{AlGaSb}$ increases monotonically. At high temperatures in the range between $580^{\circ} \mathrm{C}$ and $600^{\circ} \mathrm{C}$, the growth rate is constant. Further increasing the growth temperature lead to a decrease of the growth rate due to desorption of gallium and antimony from the growth surface. A growth rate activation energy of $0.73 \mathrm{eV}$ was found.

\section{Acknowledgment}

The authors would like to acknowledge the Ministry of Research, Technology and Higher Education (Kemenristek dan Dikti) THE REPUBLIK OF INDONESIA for financial assistance.

\section{References}

1. A.G. Milnes and A.Y. Polyakov, Solid State Electron.36, 803, (1993).

2. L. Li-Gong, LIU Shu-Man, Luo Shuai, Yang Tao, Wang Li-Jun, Liu Feng-Qi, Ye Xiao-Ling, Xu Bo, Wang Zhan-Guo Li, Chin.Phys. Lett. 29, 076801, (2012).

3. S. Mallick, Banerjee K, Ghosh S, Rodriguez J B and Krishna S., IEEE Photon. Technol. Lett., 19, 1843, (2007).

4. S.A.Pour, Huang E K, Chen G, Haddadi A, Nguyen B M and Razeghi M, Appl. Phys. Lett., 98, 143501, (2011).

5. N. Gautam, Naydenkov M, Myers S, Barve A V, Plis E, Rotter T, Dawson L R and Krishna S., Appl. Phys. Lett. 98, 121106, (2011).

6. R.M. Biefeld, Mater. Sci. Eng. R 36, 105, (2002).

7. Aardvark, Mason N J and Walker P J., Prog. Cryst. Growth Charact. 35, 207, (1997). 
8. D. Lubyshev, J.M. Fastenau, X.M. Fang, Y. Wu, C. Doss, A. Snyder, W.K. Liu, M.S. Lamb, S. Bals, and C. Song, J. Vac. Sci. Technol. B, 22, 1565, (2004).

9. C.B. Cooper, R.P. Saxena and M.J. Ludowise, Electron. Lett.16, 892, (1980).

10. M. Leroux, A. Tromson-Carli, P. Gibart, C. Verie, C. Bernard and M.C. Schouler, J.Crystal Growth, 48, 367, (1990).

11. A. Tromson-Carli, P. Gibart and C. Bernard, J. Crystal Growth 55, 70, (1981).

12. E.T.R Chidley, S.K. Haywood, R.E. Mallard, N.J. Manson, R.J. Nicholas, P.J. Walker and R.J. Warburton, J. Crystal Growth 93, 70, (1988).
13. F.S. Juang, Y.K. Su, N.Y. Li and K.J. Gan, J. Appl. Phys., 68, 6383, (1990).

14. T. Koljonen, M. Sopanen, H. Lipsanen and T. Tuomi, J. Crystal Growth 169, 417, (1996).

15. Ch. Ungermanns, H. Hardtdegen, M. Matt, A. Foster, R. Ahe Mvd, R. Carius, R. Schmidt, and Luth, J. Crystal Growth, 188, 32, (1998).

16. H. Asahi, T. Kaneko, Y. Okuno, and S. Gonda, Jpn. J. Appl. Phys.32, 2786, (1993).

17. T. Koljonen, M. Sopanen, H. Lipsanen and T. Tuomi, J. Electron. Mat. 24, 1691, (1995).

18. Y. Okuno, H. Asahi, X.F. Liu, K. Inoue, Y. Itani, K. Asami and S. Gonda, J. Crystal Growth 123, 143, (1993) 